\title{
Two Ways of High-Energy Heavy Ion Interactions: Spallation and Burst
}

\author{
Reinhard Brandt' ${ }^{1}$, Valery Ditlov' , Maria Haiduc ${ }^{3}$, Elena Firu ${ }^{3}$, Alina Tania Neagu ${ }^{3}$, \\ Eberhard Ganssauge ${ }^{4}$, Reza Hashemi-Nezhad ${ }^{5}$, Wolfram Westmeier 6 \\ ${ }^{1}$ Kernchemie, FB Chemie, Philipps-Universität Marburg, Marburg, Germany \\ ${ }^{2}$ Alikhanov Institute of Theoretical and Experimental Physics, Moscow, Russia \\ ${ }^{3}$ Bucharest Institute of Space Sciences, Bucharest, Romania \\ ${ }^{4}$ Fachbereich Physik, Philipps-Universität Marburg, Marburg, Germany \\ ${ }^{5}$ School of Physics, University of Sydney, Sydney, Australia \\ ${ }^{6} \mathrm{Dr}$. Westmeier GmbH, Ebsdorfergrund, Germany \\ Email: info@westmeier.com
}

Received 5 February 2015; accepted 9 April 2015; published 10 April 2015

Copyright (C) 2015 by authors and Scientific Research Publishing Inc.

This work is licensed under the Creative Commons Attribution International License (CC BY). http://creativecommons.org/licenses/by/4.0/

c) (i) Open Access

\begin{abstract}
A new approach to solving the observation of enhanced neutron production in high-energy heavy ion induced reactions in thick targets is presented. Two different reaction mechanisms in these interactions are considered: 1) Limited fragmentation of the projectile, called SPALLATION; 2) Complete nuclear fragmentation of the projectile fragment into individual relativistic hadrons only, referred to as "BURST". The abundance of this second path increases with the charge and energy of the projectile and may be responsible for enhanced neutron production observed with radiochemical methods in $44 \mathrm{GeV}^{12} \mathrm{C}$ and $72 \mathrm{GeV}{ }^{40} \mathrm{Ar}$ irradiations. Interactions of $72 \mathrm{GeV}^{22} \mathrm{Ne}$ in nuclear emulsions show that SPALLATION and BURST have strongly different interaction signatures, and also that the rate of BURSTS increases from $(26 \pm 3) \%$ of all interactions in the $1^{\text {st }}$ generation to $(78 \pm 6) \%$ in the $2^{\text {nd }}$ generation. Further experimental signatures of BURSTS will be described; however, no model based on physics concepts can be presented. This effect may have practical consequences for neutron safety considerations in the construction of advanced heavy ion accelerators.
\end{abstract}

\section{Keywords}

Thick Target, High Energy Projectile, Unresolved Problems, BURST

\section{Introduction}

This paper introduces two terms into the discussion of mechanisms of high-energy heavy ion induced reactions

How to cite this paper: Brandt, R., Ditlov, V., Haiduc, M., Firu, E., Neagu, A.T., Ganssauge, E., Hashemi-Nezhad, R. and Westmeier, W. (2015) Two Ways of High-Energy Heavy Ion Interactions: Spallation and Burst. World Journal of Nuclear Science and Technology, 5, 73-87. http://dx.doi.org/10.4236/wjnst.2015.52007 
in thick targets:

In SPALLATION reactions at least one heavy fragment with nuclear charge $\mathrm{Z} \geq 2$ among the projectile fragments is observed.

In BURST reactions the complete fragmentation of the projectile or projectile fragments, and possibly also of part of the target nucleus, into single relativistic hadrons is observed in nuclear emulsion (the registered tracks are called "shower tracks").

Several unresolved problems have been described in high-energy heavy ion interactions in thick targets with $44 \mathrm{GeV}^{12} \mathrm{C}$ ions at the JINR, Dubna (Russia) and $72 \mathrm{GeV}{ }^{40} \mathrm{Ar}$ at LBNL (Berkeley, USA) [1]-[3]. One of these problems is an enhanced neutron emission beyond MCNPX 2.7a-model calculations observed in irradiations of $20 \mathrm{~cm}$ extended, or thick $\mathrm{Cu}$ - and Pb-targets [2]. Such unresolved problems occur only above a center-of-mass energy $\mathrm{E}_{\mathrm{CM}} / \mathrm{u} \approx 150 \mathrm{MeV}$. Details have been discussed in [3], including a possible connection with an idea of Hagedorn dating from 1965. In order to find an explanation of these phenomena, the authors follow a suggestion of the late Professor E. Schopper (Frankfurt, Germany) [4] who recalled that Tolstov [5] had already in 1991 described experimental observations in nuclear emulsions which in the present paper are defined as BURSTS. Tolstov found a probability for this process of $3.0 \% \pm 0.3 \%$ in all nuclear interactions induced by protons in the energy range from $10 \mathrm{GeV}$ up to $400 \mathrm{GeV}$. The BURST-rate increases to approx. 30\% of all interactions, when the projectile mass is increased to $\mathrm{A}=32$ as measured in experiments at the Synchrophasotron in Dubna which provided ion beams with a momentum of up to $4.5 \mathrm{GeV} / \mathrm{c}$ per nucleon.

These two different reaction paths shall be discussed in detail. The experimental observations have been made with high-energy heavy ions irradiating nuclear emulsions, as well as in thick $\mathrm{Cu}$ - and $\mathrm{Pb}$-targets using radiochemical techniques.

- SPALLATION: In this reaction channel one observes in nuclear emulsion a clear separation between relativistic projectile-like fragments (called "minimum ionizing” or "shower" tracks) and low-energy evaporation fragments (called "black" and "grey" tracks). The essential feature of a spallation reaction is that at least ONE relativistic projectile-like fragment has a nuclear charge Z greater or equal to 2 . In addition, relativistic projectile-like fragments are emitted into a narrow angular cone in the forward direction. This definition is not strictly identical with the term spallation used in radiochemical studies. In radiochemical terminology, the word spallation is used for the observation of any target-like reaction product with a charge $(Z \geq 2)[6]$.

- BURST: This term is introduced in this paper and describes nuclear interactions observed in nuclear emulsions with exactly ZERO relativistic heavy shower particles having nuclear charge $(Z \geq 2)$. All relativistic fragments are singly charged (or neutrons). This reaction path is quite unusual, as one observes nearly always a few relativistic alpha particles. BURST events produce considerably more relativistic projectile fragments (shower particles) as compared to SPALLATION and these are emitted into a very wide angular cone, sometimes nearly into $4 \pi$-sr geometry. It will be shown that the enhanced emission of secondary neutrons in interactions within thick targets may be connected with this BURST reaction path. In this paper several phenomena of BURST reactions are described, but no attempt is made to explain this phenomenon.

Both reaction mechanisms will be discussed in detail in Sections 2 and 3. Section 4 will describe the possible correlation of the BURST mechanism with the observation of enhanced emission of secondary neutrons. Conclusions are presented in Section 5.

\section{Spallation Reactions}

\subsection{Spallation Reactions Studied in Nuclear Emulsion}

Spallation reactions have frequently been described, for example in [1]-[3] [6]. Basic concepts were presented by Cumming et al. [6] and they are understood to a large extent both in radiochemical experiments, as well as in emulsion studies - with the exception of some phenomena termed unresolved problems [7]. A typical microphotographic picture of a spallation reaction is shown in Figure $\mathbf{1}(\mathbf{b})$.

- Friedlander et al. [8] observed in nuclear emulsion irradiated with $100 \mathrm{GeV}{ }^{56} \mathrm{Fe}$ and $32 \mathrm{GeV}{ }^{16} \mathrm{O}$ a statistically significant, however small (approximately $10 \%$ to $20 \%$ ), reduction of the mean-free-path for secondary fragments with charge $(Z>2)$ on the first $10 \mathrm{~cm}$ of their flight path. Due to the small size of this effect and because of complex analytical procedures, this observation started a controversial scientific debate, as reviewed by Ganssauge [9]. However, this small effect has not been considered strong enough to be responsible for the observed increase of the enhanced emission of secondary neutrons in radiochemical experiments. 


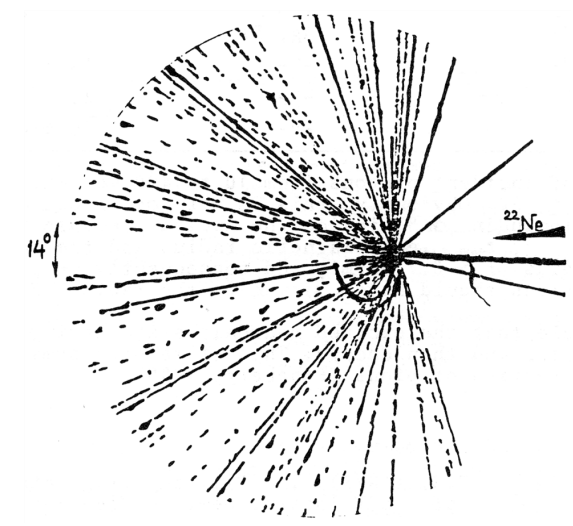

(a)

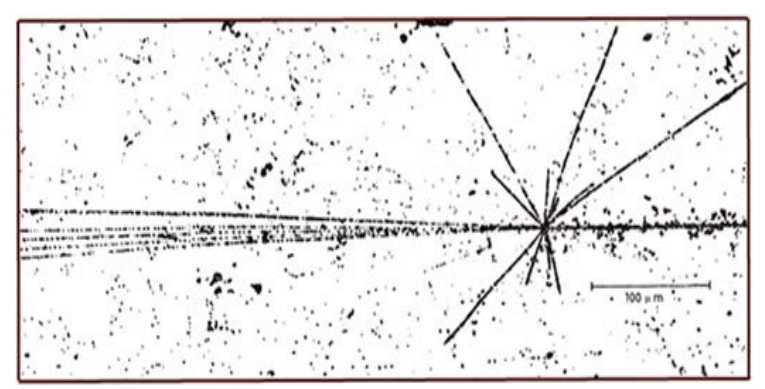

(b)

Figure 1. Micro-photographic pictures of a BURST reaction and a SPALLATION reaction. (a) BURST reaction due to $4.5 \mathrm{AGeV} / \mathrm{C}^{22} \mathrm{Ne}$ ion in nuclear emulsion with abundant production of relativistic projectile fragments. ONLY tracks with $\mathrm{Z}=1$ are observed by Tolstov [5]. The identical length of all tracks in the picture is due to this presentation. The real track lengths are not given. The empty gap of 14 degrees (no tracks are observed) in the forward direction is real. Such gaps are frequently observed; they will be discussed later in more detail; (b) SPALLATION reaction with a clear separation of small-angle forward emitted projectile fragments (thin tracks) and the isotropic emission of black prongs from the residual target nucleus as reported by Ganssauge [1].

- Ganssauge et al. [1] studied SPALLATION interactions of $100 \mathrm{GeV}{ }^{56} \mathrm{Fe}$ in nuclear emulsion and observed for projectile-like alpha fragments, that these either originate from a source with a temperature of $\sim 40 \mathrm{MeV}$ (20\%) or of $\sim 10 \mathrm{MeV}$ (80\%). Surprisingly, the temperature of the source which emits target-like protons had always a temperature around $(10-12) \mathrm{MeV}$ in both reaction channels. The authors did not present definite conclusions. Instead, they suggested adopting an image introduced by Szilard [10] in 1929, where he proposed the allegory of "intelligente Wesen" in connection with such phenomena.

- Westmeier et al. [3] have shown, that all unresolved problems in high-energy heavy ion interactions in thick targets were ONLY observed above a threshold in the center-of-mass energy $\mathrm{E}_{\mathrm{CM}} / \mathrm{u} \approx 150 \mathrm{MeV}$ both for radiochemical and emulsion SPALLATION studies, as well as for the observation of enhanced emission of secondary neutrons.

\subsection{Spallation Reactions Studied with Radiochemical Methods in Cu-Targets}

The production of radioactive spallation products in $20 \mathrm{~cm}$ thick Cu-targets in a series of heavy ion irradiations has been studied with radiochemical methods. In such thick targets both primary and secondary fragments make reactions and produce radioactive nuclides. In the context of the present article, one special aspect will be considered: "Can the detailed analysis of the production rate of radioactive spallation products provide an understanding of the enhanced emission of secondary neutrons above the threshold of $\mathrm{E}_{\mathrm{CM}} / \mathrm{u} \approx 150 \mathrm{MeV}$ ?" An attempt has been made to extract from radiochemical spallation yield measurements information on the average mass $<\mathrm{A}>$ of all spallation products produced in these interactions. Five irradiations with heavy ions onto $20 \mathrm{~cm}$ thick Cu-targets (20 disks of $1 \mathrm{~cm}$ thickness each) were investigated in Dubna and Berkeley with the identical analytical methods. The projectiles were:

- in Dubna: $3 \mathrm{GeV}^{2} \mathrm{H}, 7.4 \mathrm{GeV}^{2} \mathrm{H}, 18 \mathrm{GeV}^{12} \mathrm{C}$, and $44 \mathrm{GeV}^{12} \mathrm{C}$,

- in Berkeley: $72 \mathrm{GeV}^{40} \mathrm{Ar}$.

Two of the above reactions, namely $3 \mathrm{GeV}^{2} \mathrm{H}$ and $7.4 \mathrm{GeV}^{2} \mathrm{H}$ on copper, are below the $\mathrm{E}_{\mathrm{CM}} / \mathrm{u} \approx 150 \mathrm{MeV}$ threshold. Among the radioactive spallation nuclei formed in these interactions, the following 7 nuclides were selected for the estimation of the average mass $<\mathrm{A}>$ of all spallation products formed:

$$
{ }^{24} \mathrm{Na},{ }^{43} \mathrm{~K},{ }^{44} \mathrm{Sc},{ }^{46} \mathrm{Sc},{ }^{54} \mathrm{Mn},{ }^{57} \mathrm{Ni},{ }^{59} \mathrm{Fe}
$$

The analysis considered the $1^{\text {st }}, 2^{\text {nd }}, 4^{\text {th }}, 6^{\text {th }}, 8^{\text {th }}$, and $10^{\text {th }}$ Cu-disk, as these 6 Cu-disks $(1 \mathrm{~cm}$ thickness, $8 \mathrm{~cm}$ diameter) are the only ones that were measured in all five irradiations. Several gamma-ray spectra were measured from each disk in a calibrated set-up for about 1 hour each during a total period of about 10 days after-endof-bombardment. One obtained the activity in [Bq per Cu-disk] of each isotope at the end-of-bombardment. This activity can be converted into a production cross-section for the isotope. The determination of all production 
cross-sections in one irradiation allows the estimation of a product yield distribution. The calculation of an average mass $<\mathrm{A}>$ of such a spallation mass-yield distribution in the thick Cu-target is then a mathematical standard procedure. The details and basic experimental results are described in [7] and in the Ph.D. Theses of M. Ochs [11] and G. Haase [12].

Some results are presented in Table 1.

Table 1 shows that there is a drop in the average spallation product mass from $<\mathrm{A}>=(52.5 \pm 1.8)$ for reactions below $\mathrm{E}_{\mathrm{CM}} / \mathrm{u} \approx 150 \mathrm{MeV}$ to $<\mathrm{A}>=(51.3 \pm 1.3)$ for reactions above. The average number of nucleons emitted in the spallation reaction is around

$$
\Delta \mathrm{A}=63.3-\langle\mathrm{A}\rangle=(63.3-51.7)=11.5
$$

However, caution is advised here, as the selection of only 7 spallation products in 6 out of 20 Cu-disks is rather limited and arbitrary. Nevertheless one can see that there is a striking similarity in the observed $<\mathrm{A}>$ for 72 $\mathrm{GeV}^{40} \mathrm{Ar}$ and $44 \mathrm{GeV}{ }^{12} \mathrm{C}$ reactions. This could imply that the observed SPALLATION reactions are comparable in both cases. An enhancement and surprisingly large neutron fluence beyond theoretical expectation was measured and analyzed for the irradiation of $20 \mathrm{~cm}$ thick $\mathrm{Cu}$ - and Pb-targets with $44 \mathrm{GeV}^{12} \mathrm{C}$ [2] [7], whereas a surprisingly large neutron fluence has only been observed but not quantified for the exposure of a $20 \mathrm{~cm} C u$ target to $72 \mathrm{GeV}^{40} \mathrm{Ar}$ [1] [7]. The results shown in Table 1 support the conclusion that during both irradiations in Berkeley and Dubna rather similar physical processes took place.

One can deduce that on average about 11.5 nucleons (protons and neutrons) are emitted in the spallation reaction.

\section{Burst Reactions Studied in Nuclear Emulsion}

Tolstov [5] describes reactions leading to the complete destruction of relativistic projectiles into ONLY individual single nucleons (protons and neutrons) plus pions in high energy ion induced nuclear interactions. These interactions are called BURSTS in the present paper. A typical photographic picture of such an event in nuclear emulsion is shown in Figure 1(a). One observes nearly 70 tracks due to the nuclear interaction of a $4.5 \mathrm{AGeV} / \mathrm{c}$ ${ }^{22} \mathrm{Ne}$-ion with a target nucleus inside the emulsion plate. These tracks have been emitted within an angular cone in the laboratory system of about $\pm 120^{\circ}$ around the forward beam direction. These thin tracks come from minimum ionizing $\mathrm{Z}=1$ particles having an energy above $370 \mathrm{MeV}$, or from pions above $56 \mathrm{MeV}$. No relativistic alpha-particle and no $\mathrm{Z}>2$ projectile-like fragment are observed in the forward-cone, implying that this has NOT been a SPALLATION reaction. A few tracks are black prongs coming from low-energy protons with (E < $26 \mathrm{MeV}$ ), which have been emitted from the residual target nucleus. Such BURSTs have been observed in a number of experiments using nuclear emulsion. Tolstov reported a BURST-rate of $3.0 \% \pm 0.3 \%$ in all proton induced reactions between $10 \mathrm{GeV}$ and $400 \mathrm{GeV}$. However, using $4.5 \mathrm{AGeV} / \mathrm{c}$ high-energy heavy ion beams from the Synchrophasotron in Dubna, he observed in nuclear emulsions from beams of

$$
\begin{aligned}
& { }^{4} \mathrm{He} \text { about }(7 \pm 1) \% \text { BURSTS, } \\
& { }^{12} \mathrm{C} \text { about }(18 \pm 2) \% \text { BURSTS, } \\
& { }^{22} \mathrm{Ne} \text { about }(20 \pm 2) \% \text { BURSTS, } \\
& { }^{28} \mathrm{Si} \text { about }(26 \pm 4) \% \text { BURSTS. }
\end{aligned}
$$

No additional details have been reported by Tolstov, who continued his research by studying the integral neutron emission in a THICK Pb-target $\left(0.5 \times 0.5 \times 0.8 \mathrm{~m}^{3}\right)$ irradiated with $3.65 \mathrm{AGeV}{ }^{1} \mathrm{H},{ }^{4} \mathrm{He}$, and ${ }^{12} \mathrm{C}$ ions. He

Table 1. Average mass $<\mathrm{A}>$ of the spallation mass-yield curve for 5 different heavy ion beams irradiating a $20 \mathrm{~cm}$ thick $\mathrm{Cu}-$ target.

\begin{tabular}{cccc}
\hline Beam & $\mathrm{E}_{\mathrm{CM}} / \mathrm{u}(*)$ & $<\mathrm{A}>(\mathrm{amu})$ & \\
\hline $3 \mathrm{GeV}^{2} \mathrm{H}$ & $43 \mathrm{MeV}$ & $52.4 \pm 2.6$ & $\mathrm{E}_{\mathrm{CM}} / \mathrm{u}<150 \mathrm{MeV}$ \\
$7.4 \mathrm{GeV}^{2} \mathrm{H}$ & $107 \mathrm{MeV}$ & $52.6 \pm 2.6$ & \\
$18 \mathrm{GeV}^{12} \mathrm{C}$ & $194 \mathrm{MeV}$ & $51.8 \pm 4.1$ & $\mathrm{E}_{\mathrm{CM}} / \mathrm{u}>150 \mathrm{MeV}$ \\
$44 \mathrm{GeV}^{12} \mathrm{C}$ & $488 \mathrm{MeV}$ & $51.3 \pm 4.1$ & \\
$72 \mathrm{GeV}^{40} \mathrm{Ar}$ & $426 \mathrm{MeV}$ & $51.3 \pm 1.5$ & \\
\hline
\end{tabular}

$\left.{ }^{*}\right) \mathrm{E}_{\mathrm{CM}} / \mathrm{u}$ in $\mathrm{MeV}$ is the center-of-mass energy per nucleon in the entrance channel. 
measured the neutron fluence induced by secondary neutrons with radiochemical methods and found for 3.65 $\mathrm{AGeV}{ }^{1} \mathrm{H}$ and ${ }^{4} \mathrm{He}$ irradiations exactly the neutron fluence which is calculated with current models, whereas for 3.65 $\mathrm{AGeV}{ }^{12} \mathrm{C}$ irradiations, a significantly larger neutron fluence than calculated.

This finding was reviewed in [13].

Two recent studies on the observations of BURST and SPALLATION reactions induced by $72 \mathrm{GeV}{ }^{22} \mathrm{Ne}$ heavy ions in nuclear emulsions are presented.

$\underline{1}^{\text {st }}$ Study: Ditlov et al. [14] [15] carried out a "Study of the number of 'black prongs', $N_{b}$, in two generations of nuclear interactions in photo-emulsions irradiated with $72 \mathrm{GeV}^{22} \mathrm{Ne}$ ". They separated the observed nuclear reactions into two classes: BURST and SPALLATION, using the same criteria as in the present paper.

- BURST events, $\mathrm{N}$ [BUR], with ZERO heavy relativistic fragments having $\mathrm{Z}>1$, and

- SPALLATION events, $\mathrm{N}$ [SPA], with more than ZERO heavy relativistic fragments.

The aim of this study was to measure the number, $\mathrm{N}_{\mathrm{b}}$, of black prongs (protons with $\mathrm{E}<26 \mathrm{MeV}$ ) per interaction in the first (primary) interaction and the second (consecutive) interaction of $72 \mathrm{GeV}^{22} \mathrm{Ne}$-ions in nuclear emulsion. The black prongs, $\mathrm{N}_{\mathrm{b}}$, are emitted from the residual target nucleus after the fast cascade interaction. Results are shown in Table 2, using the data set from [15].

Table 2 shows that:

- $112 / 427=(26 \pm 4) \%$ of all first reactions are BURST reactions. This is slightly larger than the ratio presented by Tolstov $(20 \pm 2) \%$ [5]. However, the real surprise is the result for the $2^{\text {nd }}$ generation where 100/142 $=(70 \pm 8) \%$ of all reactions are BURSTS. This is more than twice as much as in the $1^{\text {st }}$ generation.

- There is no theoretical model known to the authors, which can explain the relative large yield of BURSTS in the $1^{\text {st }}$ generation. It is also an unresolved problem as to why the prevalence of BURSTS increases drastically in the 2nd generation.

- The average number of black prongs, $<\mathrm{Nb}>$, in the 1st generation is substantially larger for BURST, as compared to the average number of black prongs in SPALLATION reactions by a factor of $(11.8 \pm 0.5) /(4.4$ $\pm 0.2)=2.7 \pm 0.3$ This may be the reason why in THICK target irradiations with $44 \mathrm{GeV}^{12} \mathrm{C}$ and $72 \mathrm{GeV}$

${ }^{40} \mathrm{Ar}$ ions, one observes in radiochemical experiments systematically larger neutron yields than expected from model calculations in which only SPALLATION reactions are considered. This problem will be discussed in more detail in the next section.

- The N(SPA) events include both hot (T 40 MeV) and cold (T 10 MeV) interactions, as described [1]. The $<\mathrm{Nb}>$ is rather low both in the 1st and in the 2nd generation. This is in agreement with [1], where the same low temperature $\mathrm{T} \sim 12 \mathrm{MeV}$ is found for target-like residual nuclei in all nuclear SPALLATION interactions, both for hot and cold interactions producing relativistic projectile-like $\mathrm{Z}=2$ fragments.

The entire reaction path for $72 \mathrm{GeV}^{22} \mathrm{Ne}$ is schematically presented in Figure 2 using numerical values from [15]. It shows - taking the observed TWO generations together-that $(78 \pm 6) \%$ of all original ${ }^{22} \mathrm{Ne}$-tracks finally lead to BURST interactions along their reaction path in nuclear emulsion. We cannot distinguish if spallation reactions in the first and second generation proceed in the same way.

One observes 315 SPALLATION reactions in the first generation. However, due to the geometry of the 600 $\mu \mathrm{m}$ thin emulsion, only 142 SPALLATION reaction products are followed in the second generation. In the $\mathrm{Z}=$ 2) - channel there is a ratio of Burst/Spallation of 66/6. This implies that approx. $90 \%$ of all secondary alphas induce BURST interactions, whereas Tolstov [5] found only (7 \pm 1$) \%$ BURST reactions in the first interaction induced by alpha projectiles in the same energy range. This confirms that secondary alphas transfer signifi-

\begin{tabular}{ccccc}
\multicolumn{4}{c}{ Table 2. Event numbers and multiplicities in $1^{\text {st }}$ and $2^{\text {nd }}$ generation of $72 \mathrm{GeV}^{22} \mathrm{Ne}$ reactions. } \\
\hline & $1^{\text {st }}$ generation N (events) & $1^{\text {st }}$ generation $<\mathrm{N}_{\mathrm{b}}>$ & $2^{\text {nd }}$ generation $\mathrm{N}$ (events) & $2^{\text {nd }}$ generation $<\mathrm{N}_{\mathrm{b}}>$ \\
\hline Burst + Spallation & 427 & $6.3 \pm 0.2$ & 142 & $6.3 \pm 0.3$ \\
Burst (BUR) & 112 & $11.8 \pm 1.2$ & 100 & $7.0 \pm 0.7$ \\
Spallation (SPA) & 315 & $4.4 \pm 0.2$ & 42 & $4.7 \pm 0.5$ \\
(BUR)/(SPA) & $112 / 315=0.36$ & $11.8 / 4.4=2.6$ & $100 / 42=2.4$ & $7.0 / 4.7=1.5$ \\
(BUR)/total & $112 / 427=0.26$ & $11.8 / 6.3=1.87$ & $100 / 142=0.70$ & $7.0 / 6.3=1.11$ \\
\hline
\end{tabular}

$<\mathrm{N}_{\mathrm{b}}>$ is the average number of black prongs per event. 


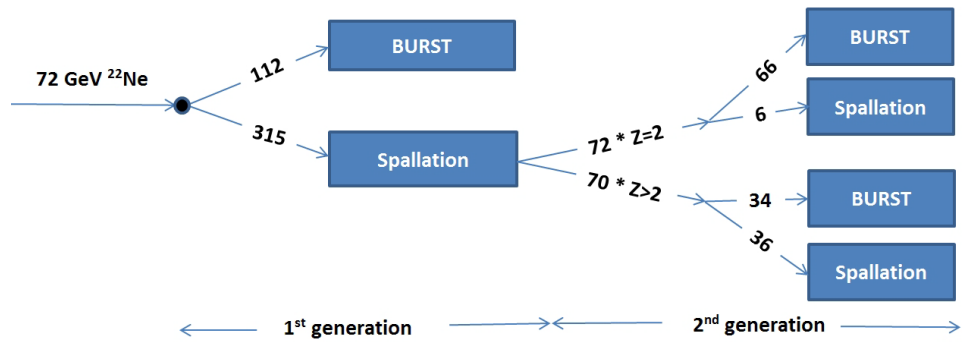

Figure 2. Schematic presentation of the two reaction paths BURST or SPALLATION in the $1^{\text {st }}$ and $2^{\text {nd }}$ interactions of $72 \mathrm{GeV}^{22} \mathrm{Ne}$ and its reaction products. In the second generation Helium nuclei induce predominantly BURSTS. This figure is based on the data set of [15].

cantly more energy than primary alphas do [3].

Ditlov et al. [14] [15] have also published the distribution of black prongs, $\mathrm{N}_{\mathrm{b}}$, for both the BURST path, as well as for SPALLATION as shown in Figure 3. The $\mathrm{N}_{\mathrm{b}}$-distribution shows no surprise for SPALLATION reactions: Its maximum is at $\mathrm{N}_{\mathrm{b}}=0$ as expected from the impact parameter favoring peripheral interactions with low energy transfer, and it decreases continuously towards lower values with increasing $\mathrm{N}_{\mathrm{b}}$. This is in agreement with calculations based on conventional concepts like limiting fragmentation [7].

However, the $\mathrm{N}_{\mathrm{b}}$-distribution for BURST reactions gives a completely different picture, which is not predicted by any model known to the authors. The distribution looks a little chaotic with its two maxima. The first one is around small $\mathrm{N}_{\mathrm{b}}$-values (possibly due to reactions with light CNO-nuclei within the emulsion) and the other maximum is around $\mathrm{N}_{\mathrm{b}}=16$ which might originate from interactions with Ag- or Br-nuclei in the emulsion. Additional research is needed in order to understand the BURST reaction mechanism.

The ratio of mean values $<\mathrm{N}_{\mathrm{b}}>$ for BURST (BUR) to SPALLATION (SPA) is:

$$
\left(\text { Ratio BUR/SPA for }\left\langle\mathrm{N}_{\mathrm{b}}\right\rangle\right)_{\text {Ditlov }}=(11.8 \pm 0.4) /(4.4 \pm 0.2)=2.68 \pm 0.15
$$

$2^{\text {nd }}$ Study: Haiduc et al. [16] contributed independent results from studies in nuclear emulsion irradiated with high-energy heavy ions. Their studies of irradiations with $72 \mathrm{GeV}^{22} \mathrm{Ne}$ are focused only on the $1^{\text {st }}$ interactions of primary ions; however, they involve a very large number of interactions. They present an additional detail in that they include the measurement of the number and angular distribution of minimum ionizing particles (mostly $\mathrm{Z}=1$ nucleons with energy above $370 \mathrm{MeV}$ and relativistic pions) for BURST and SPALLATION reactions. Haiduc et al. selected these two channels with the same criteria as used hitherto in this paper. The results are shown in Figure 4.

It is very obvious that the distributions for these two reaction channels are completely different.

Top row: The angular distribution of minimum ionizing particles, $\mathrm{N}_{\mathrm{s}}$, gives the distribution of the polar angle $\Theta$ with respect to the beam direction. This distribution can be completely understood with conventional models for SPALLATION reactions (Figure 4, Top row, right). It has its maximum in the beam direction $\left(\Theta=0^{\circ}\right)$. One observes within the first two bins about $(6000 / 25635)=23 \%$ of all interactions. A narrow cone of $\Theta \approx 3^{\circ}$ is expected because of the Fermi motion of nucleons. (Note: The number 6000 is the number of events within the angular range from $0^{\circ}$ up to $\Theta=3^{\circ}$, the number 25,635 is the total number of events in all angles measured, data taken from tables of Haiduc et al. [16]. All following equivalent numbers of events have the same meaning.)

For BURSTS one clearly observes a broader angular distribution. In the first two bins one finds only about (2400/25193=) 9\% of all interactions. This contribution is considerably lower than in SPALLATION. It may in part also be due to occasional events having ZERO Ns-tracks in the forward direction (see Figure 1(a)). The first angular bin $\left(\Theta<2^{\circ}\right)$ contains less events (appr. 1100 events) than the second angular bin $\left(2^{\circ}<\Theta<4^{\circ}\right)$ which holds approximately 1340 events. The maximum in this angular distribution is not found exactly in the beam direction! This very strange phenomenon will be discussed in more detail later.

Middle row: The distribution of numbers of $\mathrm{N}_{\mathrm{s}}$-events for SPALLATION reactions can again be understood completely with conventional models. It has the maximum of $\mathrm{N}_{\mathrm{s}}$-tracks in the beam direction $\left(\Theta=0^{\circ}\right)$. Within the first two bins $\left(\mathrm{N}_{\mathrm{s}}<3\right)$ there are $(900 / 3251)=27 \%$ of all interactions. In BURST reactions, however, one finds within the first two bins $\left(\mathrm{N}_{\mathrm{s}}<3\right)$ almost ZERO interactions. The maximum is around $\mathrm{N}_{\mathrm{s}}=27$. The ratio of mean values $<\mathrm{N}_{\mathrm{s}}>$ for BURST (BUR) to SPALLATION (SPA) is

$$
\left(\text { Ratio BUR/SPA for }\left\langle\mathrm{N}_{\mathrm{s}}\right\rangle\right)_{\text {Haiduc }}=(26.68 \pm 0.05) /(7.62 \pm 0.24)=3.50 \pm 0.10
$$

i.e. there are over three times more relativistic protons in BURSTS than in SPALLATION. 

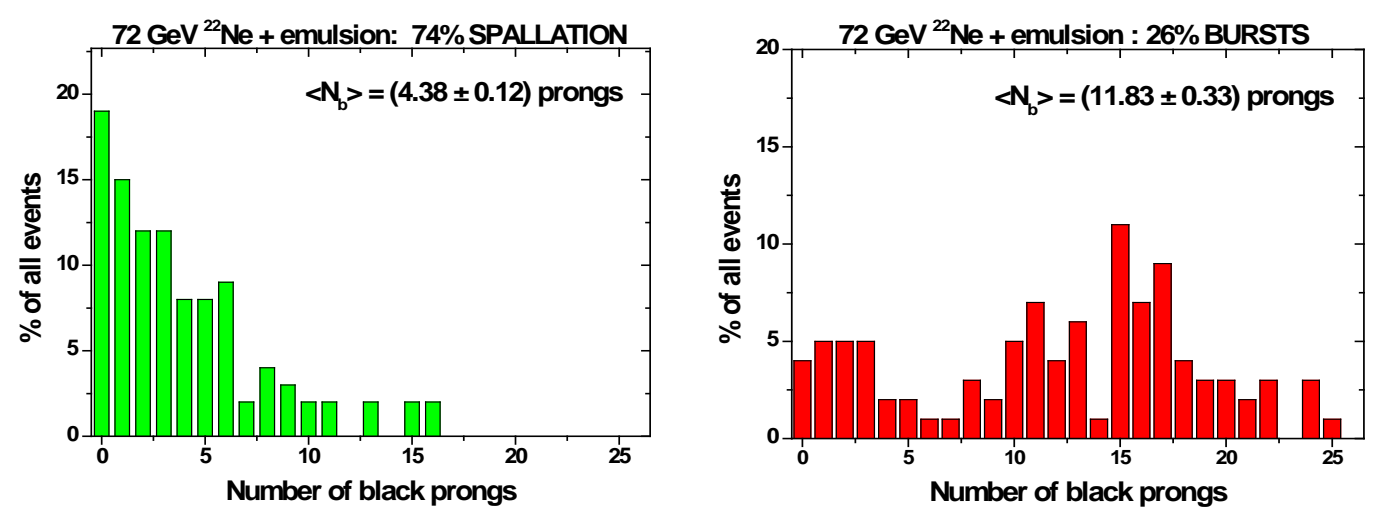

Figure 3. The $\mathrm{N}_{\mathrm{b}}$ distribution observed in the $1^{\text {st }}$ generation of a nuclear reaction as sketched in Figure 2 for SPALLATION and BURST reactions according to [15].
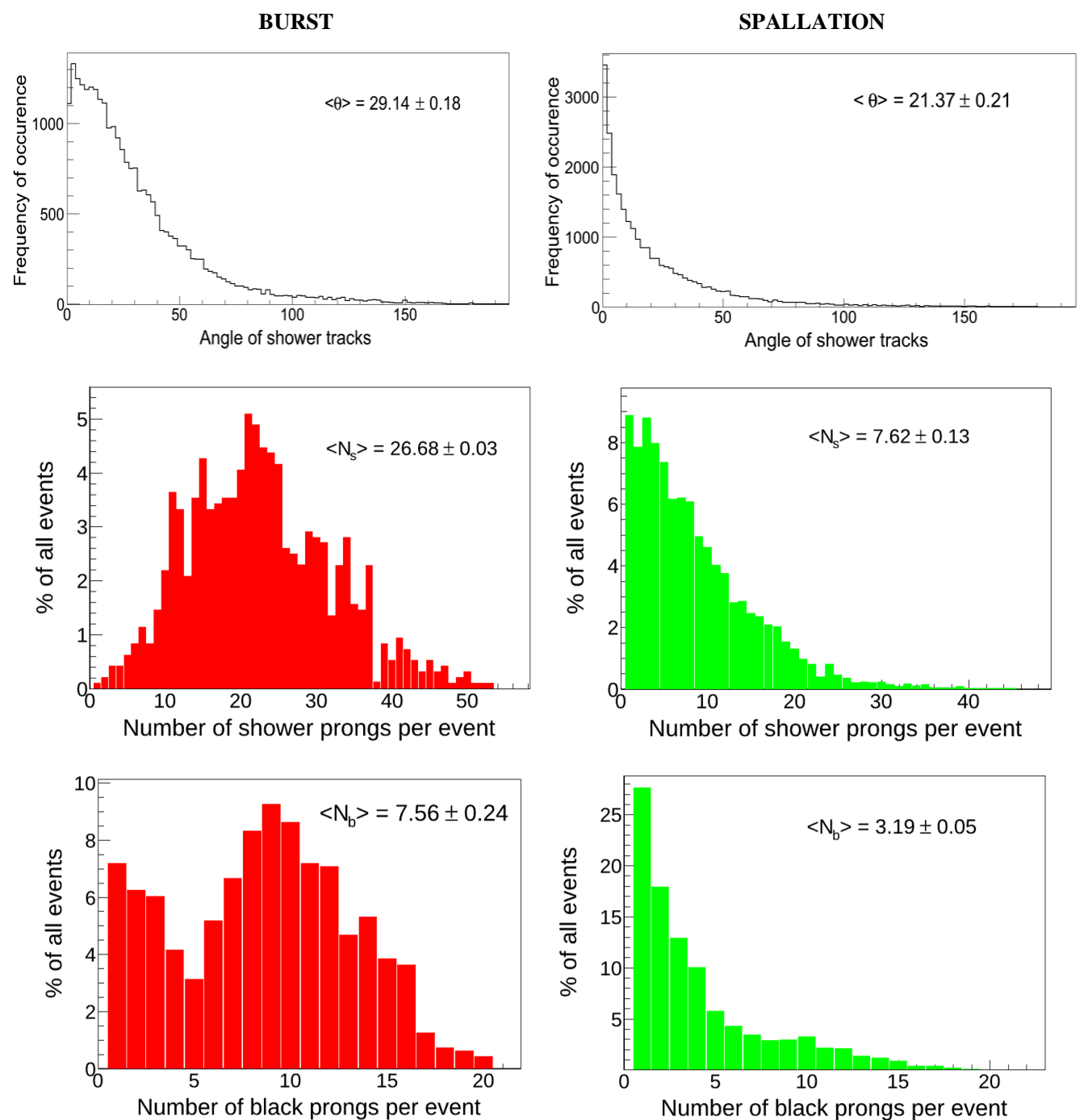

Figure 4. Comparison of track properties in the interaction of $72 \mathrm{GeV}^{22} \mathrm{Ne}$ in emulsion [16]. Top row: Polar angulardistribution ofminimum ionizingparticles, $\mathrm{N}_{\mathrm{s}}$, measured relative to the beam; Middle row: Frequency distribution of the number of minimum ionizing particles, $\mathrm{N}_{\mathrm{s}}$; Bottom row: Frequency distribution of the number of black prongs, $\mathrm{N}_{\mathrm{b}}$. 
Bottom row: A similar distribution of $\mathrm{N}_{\mathrm{b}}$-events has already been shown by Ditlov for the reaction of ${ }^{22} \mathrm{Ne}-$ ions. Haiduc et al. carried out the same investigation on a larger sample and found in both channels slightly lower values for $\left\langle\mathrm{N}_{\mathrm{b}}>\right.$. However, they observed nearly the same $<\mathrm{N}_{\mathrm{b}}>$-ratio for BURST (BUR) over SPALLATION (SPA) as Ditlov:

$$
\begin{gathered}
\left(\text { Ratio BUR/SPA for }\left\langle\mathrm{N}_{\mathrm{b}}\right\rangle\right)_{\text {Haiduc }}=(7.56 \pm 0.24) /(3.19 \pm 0.05)=2.34 \pm 0.09 \\
\left(\text { Ratio BUR/SPA for }\left\langle\mathrm{N}_{\mathrm{b}}\right\rangle\right)_{\text {Ditlov }}=(11.8 \pm 0.4) /(4.4 \pm 0.2)=2.68 \pm 0.15
\end{gathered}
$$

Finally, Haiduc et al. measured results of BURST and SPALLATION reactions for several other heavy ion reactions in Dubna at momentum 4.5 AGeV/c, as given in Table 3. The results of this separation into two groups are similar, however, not identical with the older result of Tolstov [5].

In addition, Haiduc et al. made another interesting observation in their study. They observed some events, called very strange events which have no particle at all in forward direction $\left(\mathrm{N}_{\mathrm{b}}=0, \mathrm{~N}_{\mathrm{s}}=0\right.$, and ZERO relativistic Helium or heavier $(\mathrm{Z}>2)$ tracks) up to $\left(\Theta= \pm 8^{\circ}\right)$. This confirms one central aspect of Tolstov's observations [5] who also reported events with no (zero) particles emitted in forward direction. They gave also further technical details, such as their emulsion plate thickness of 500 microns, and grain size in the emulsion of 0.5 microns. The geometry of a track is determined by measuring $\mathrm{x}, \mathrm{y}, \mathrm{z}$ coordinates for each track relative to the beam direction. The polar and azimuthal angles are calculated accordingly. The picture of Tolstov's BURST in Figure 1 (a) is a projection of the direction of the track onto the observation plane.

In Table 31015 events of ${ }^{22}$ Ne-induced BURST reactions are listed. Among these are 216 events (216/1015 $=21 \% \pm 3 \%)$ that are very strange events with exactly ZERO tracks within a polar angle up to $\left(\Theta= \pm 3^{\circ}\right)$ around the beam direction.

Figure 5 shows the $\mathrm{N}_{\mathrm{s}}$ - and $\mathrm{N}_{\mathrm{b}}$-distributions for very strange events among BURST interactions. It is interesting to observe: neither $\mathrm{N}_{\mathrm{s}}$-nor $\mathrm{N}_{\mathrm{b}}$-distributions have a peak at low values of $\left(\mathrm{N}_{\mathrm{s}}<20\right)$ or $\left(\mathrm{N}_{\mathrm{b}}<5\right)$, as observed in the corresponding distributions shown in Figure 4. These very strange events in Figure 5 have significantly larger multiplicities $\left(<\mathrm{N}_{\mathrm{b}}>=8.59\right)$ and $\left(<\mathrm{N}_{\mathrm{s}}>=32.43\right)$ as compared to the corresponding values for all ${ }^{22} \mathrm{Ne}-$ BURST interactions shown in Figure 4. The reasons for these observations are unclear. It is conceivable that these very strange events are associated with a larger energy release as compared to other BURSTS. In any case, these events are another contribution to "unresolved problems" discussed in recent publications [1]-[3].

These very strange events are observed up to polar angles up to $\left(\Theta= \pm 8^{\circ}\right)$ around the beam direction as shown in Table 4. The event rates decrease up to the largest angles observed. Again, there are no theoretical models known to the authors which can explain such effects.

When examining all experimentally observed properties of BURST interactions, one is not surprised that this reaction channel is not yet included in computer codes for calculating high-energy heavy ion interactions. For such an inclusion into modern codes, one must understand the basic reaction mechanism of BURST interactions.

Table 3. Numbers of first generation BURST and SPALLATION reactions in nuclear emulsion irradiated with $4.5 \mathrm{AGeV} / \mathrm{c}$ ${ }^{16} \mathrm{O},{ }^{22} \mathrm{Ne},{ }^{28} \mathrm{Si}$, and ${ }^{32} \mathrm{~S}$ ions in Dubna.

\begin{tabular}{ccc}
\hline${ }^{16}$ O-BURST & No. of events & \% of ALL events \\
\hline${ }^{16}$ O-SPALLATION & 907 & $33 \pm 2$ \\
${ }^{22}$ Ne-BURST & 1867 & $24 \pm 2$ \\
${ }^{22}$ Ne-SPALLATION & 1015 & $76 \pm 2$ \\
${ }^{28}$ Si-BURST & 3251 & $16 \pm 2$ \\
${ }^{28}$ Si-SPALLATION & 215 & $84 \pm 2$ \\
${ }^{32}$ S-BURST & 1095 & $13 \pm 2$ \\
${ }^{32}$ S-SPALLATION & 167 & $87 \pm 2$ \\
\hline
\end{tabular}


Table 4. Number of very strange events in BURST reactions of $72 \mathrm{GeV}^{22} \mathrm{Ne}$ in nuclear emulsionas function of the polar angle $\Theta$. There are ZERO tracks within this angular range.

\begin{tabular}{cccc}
\hline Polar angle $\Theta[\mathrm{deg}]$ & Number of events & $<\mathrm{N}_{\mathrm{b}}>$ & $<\mathrm{N}_{\mathrm{s}}>$ \\
\hline $0<\Theta<8$ & 14 & $9.7 \pm 2.6$ & $30.0 \pm 8.0$ \\
$0<\Theta<7$ & 20 & $8.7 \pm 1.9$ & $32.0 \pm 7.2$ \\
$0<\Theta<6$ & 40 & $9.0 \pm 1.4$ & $33.0 \pm 5.4$ \\
$0<\Theta<5$ & 70 & $9.0 \pm 1.1$ & $33.5 \pm 4.0$ \\
$0<\Theta<4$ & 132 & $8.6 \pm 0.8$ & $33.0 \pm 2.9$ \\
$0<\Theta<3$ & 216 & $8.7 \pm 0.6$ & $32.4 \pm 2.2$ \\
$0<\Theta<2$ & 364 & $8.5 \pm 0.2$ & $31.3 \pm 1.6$ \\
\hline
\end{tabular}
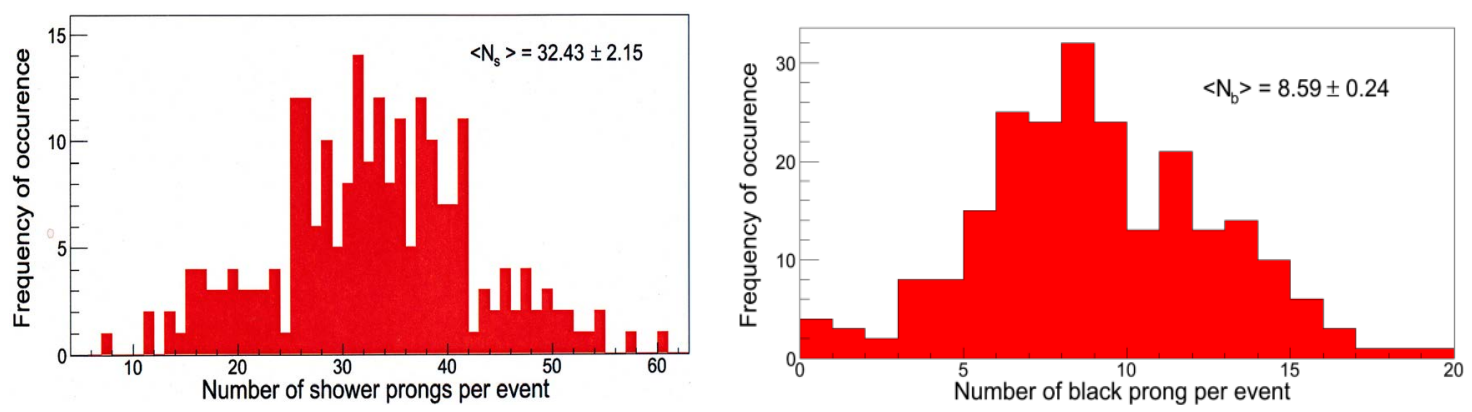

Figure 5. (Left) $\mathrm{N}_{\mathrm{s}}$ and (right) $\mathrm{N}_{\mathrm{b}}$-distributions from 228 very strange BURST reactions in irradiations with $72 \mathrm{GeV}$ ${ }^{22} \mathrm{Ne}$. These very strange events have zero events with $\mathrm{N}_{\mathrm{s}}=0\left(\mathrm{~N}_{\mathrm{s}}=\right.$ fast protons from the projectile) and only few events with $\mathrm{N}_{\mathrm{b}}=0$ ( $\mathrm{N}_{\mathrm{b}}$ = slow protons/pions from the target nucleus).

\section{Heavy Ion Induced Reactions with Thick $\mathrm{Cu}$ and $\mathrm{Pb}$ Targets}

\subsection{Spallation Yields}

For comparisons with model calculations we have used modern computer codes (DCM/CEM, LAHET, and MCNPX2a) in calculations for recent publications [1]-[3].

In this context it is interesting to look again into old radiochemical studies presented in detail in [7]. A short review may be sufficient at this place: a $1 \mathrm{~cm}$ thick Cu-target was irradiated with a well-focused heavy ion beam of either $4 \mathrm{GeV}^{4} \mathrm{He}$ or $44 \mathrm{GeV}{ }^{12} \mathrm{C}$. The primary target emitted a broad spectrum of secondary ions into wide angles. These secondary particles with angles $\left(\Theta>0^{\circ}\right)$ are high-energy protons, pions and neutrons, which could interact in some distances (between $4 \mathrm{~cm}$ up to $10 \mathrm{~cm}$ ) with five additional $1 \mathrm{~cm}$ thick Cu-rings exposed to angular intervals of $\left(0^{\circ}-10^{\circ}\right),\left(10^{\circ}-19^{\circ}\right),\left(19^{\circ}-31^{\circ}\right),\left(31^{\circ}-43^{\circ}\right)$, and $\left(43^{\circ}-52^{\circ}\right)$.

Secondary particles will induce nuclear reactions in the additional $\mathrm{Cu}$-rings, thus producing radioactive products, such as ${ }^{58} \mathrm{Co},{ }^{44} \mathrm{Sc}$, and ${ }^{24} \mathrm{Na}$, which were measured with standard radiochemical techniques. The results are shown in Figure 6 where values in percent are the ratios of sideward activities relative to the forward activity.

In the irradiation with $4 \mathrm{GeV}^{4} \mathrm{He}$ (a reaction below the threshold [3] of $\mathrm{E}_{\mathrm{CM}} / \mathrm{u} \approx 150 \mathrm{MeV}$ ) one observes within the angular interval $\left(43^{\circ}\right.$ to $\left.52^{\circ}\right)$ practically only production of the nuclide ${ }^{58} \mathrm{Co}$. This nuclide is very close in mass to the target mass of $\mathrm{Cu}(63.5 \mathrm{u})$. Only low-energy secondaries (around $100 \mathrm{MeV}$ ) are emitted into this large angle and one observes low excitation energy spallation reactions leading to the nuclide ${ }^{58} \mathrm{Co}$. In the $\mathrm{Cu}-$ rings exposed at smaller emission angles, there is a similar reaction pattern: ${ }^{58} \mathrm{Co}$ is always the most abundant spallation product, however, there are also lower-mass products $\left({ }^{44} \mathrm{Sc}\right.$ and $\left.{ }^{24} \mathrm{Na}\right)$ formed in small yields due to the harder energy spectrum of secondary fragments emitted into the more forward angles. All of this is wellunderstood by the spallation reaction mechanism.

In the irradiation with $44 \mathrm{GeV}^{12} \mathrm{C}$ (a reaction above the threshold of $\mathrm{E}_{\mathrm{CM}} / \mathrm{u} \approx 150 \mathrm{MeV}$ ) a drastically different 

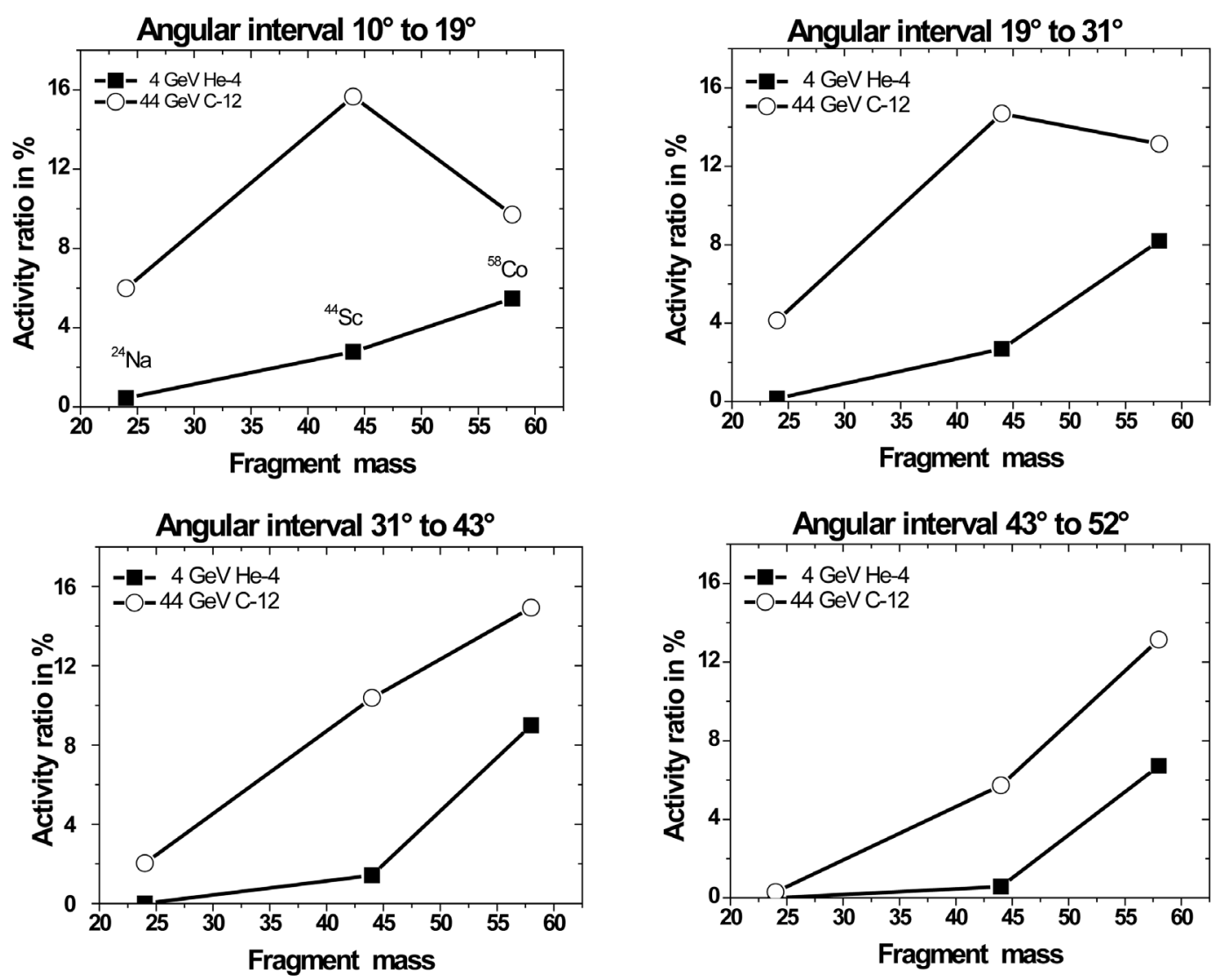

Figure 6. Three-point mass-yield curves in specific $\mathrm{Cu}$ rings produced by secondary fragments in the interaction of a copper target with $4 \mathrm{GeV}^{4} \mathrm{He}$ (solid points) and $44 \mathrm{GeV}^{12} \mathrm{C}$ (open points) ions. Yields are shown for ${ }^{24} \mathrm{Na},{ }^{44} \mathrm{Sc}$ and ${ }^{58} \mathrm{Co}$, thus covering the mass range of spallation products.

reaction product yield pattern is encountered within the lab angular interval from $10^{\circ}$ to $19^{\circ}$. The mass-yield curve now has its maximum around ${ }^{44} \mathrm{Sc}$ whereas the yields for two nuclides ${ }^{24} \mathrm{Na}$ and ${ }^{58} \mathrm{Co}$ are much lower. This yield-distribution produced by secondary fragments in a $2^{\text {nd }}$ generation reaction is completely incompatible with any conventional spallation mass-yield distribution. For larger angles, the situation becomes less drastic, but still yield distributions below $31^{\circ}$ are incompatible with well-known spallation reactions. This study was originally presented by F. Pille [17] and reviewed in [7].

Figure 6 shows that secondary fragments are emitted into large lab angles, where they interact with Cu-rings. A lot of energy is transferred into unexpectedly large angles which for example leads to significant production of ${ }^{44} \mathrm{Sc}$ in the $19^{\circ}$ to $31^{\circ}$ bin. The yield for a specific isotope in a given $\mathrm{Cu}$ ring is the ratio of its activity (in \%) in the ring compared to the activity in the forward Cu-target. The experimental uncertainty is about $\pm 8 \%$.

\subsection{Neutron Production}

High-energy heavy ion irradiations of THICK Cu- or Pb-targets have been investigated with radiochemical methods [1]-[3] [7]. Radioactive product nuclides were investigated with gamma-ray spectrometry. In addition, neutron yields could be determined indirectly with radiochemical methods [18]. There are no unresolved problems observed in the study of spallation mass yields or neutron yields in heavy-ion interactions below a bombarding energy of about $10 \mathrm{GeV}$, or more accurately, below a center-of-mass energy per nucleon of $\mathrm{E}_{\mathrm{CM}} / \mathrm{u} \approx 150$ $\mathrm{MeV}$ [3]. However, above this energy limit all experimental results cannot be understood with well-known models, thus constituting unresolved problems. In the context of this paper, the irradiations of $20 \mathrm{~cm}$ THICK $\mathrm{Cu}$ - and Pb-targets with $44 \mathrm{GeV}^{12} \mathrm{C}$ in Dubna and a $20 \mathrm{~cm}$ THICK Cu-target with $72 \mathrm{GeV}^{40} \mathrm{Ar}$ in Berkeley are of particular importance. Exceedingly large neutron fluences beyond theoretical estimations [1] were observed in irradiations with these high-energy heavy ions. The data will be re-examined with the more recent computer 
codes, MCNPX2.6 and MCNPX2.7.

\subsubsection{Dubna Experiments}

In the Dubna-experiments the so-called GAMMA-2 target [18] which is a metallic target $(\mathrm{Cu}$ or $\mathrm{Pb})$ of $20 \mathrm{~cm}$ length and $8 \mathrm{~cm}$ diameter surrounded by a $6 \mathrm{~cm}$ paraffin moderator was irradiated with heavy ions. The moderator contains holes, filled with a La-compound serving as a neutron sensor. The radioactivity induced in the sensor is quantified with standard gamma-ray spectrometry:

$$
{ }^{139} \mathrm{La}(\mathrm{n}, \gamma){ }^{140} \mathrm{La} \text {, the half-life of }{ }^{140} \mathrm{La} \text { is : } \tau_{1 / 2}=40.3 \mathrm{~h}
$$

The GAMMA-2 target was irradiated with a series of heavy ions (see Section 2.2), including $44 \mathrm{GeV}^{12} \mathrm{C}$ ions. This experiment will be re-considered here together with a recent calibration experiment using $1 \mathrm{GeV}$ protons by Westmeier et al. [19]. The authors measured the neutron production in the GAMMA-2 target with a $20 \mathrm{~cm}$ long lead core irradiated with $1 \mathrm{GeV}$ protons. They determined the neutron fluence through the measurement of the induced ${ }^{140} \mathrm{La}$-activity and obtained an experimental production rate of ${ }^{140} \mathrm{La}$, called $\mathrm{B}\left({ }^{140} \mathrm{La}\right)$ which is defined as follows:

$$
\mathrm{B}\left({ }^{140} \mathrm{La}\right)=\left(\text { number of }{ }^{140} \mathrm{La} \text { atoms formed }\right) /(1 \mathrm{~g} \mathrm{La}-\text { target }) /(1 \text { primary ion })
$$

$\mathrm{B}\left({ }^{140} \mathrm{La}\right)$-values for various samples along the target were determined experimentally and simultaneously calculated theoretically with theMCNPX2.6c code. Both, the experiment and calculation agree to better than $\pm 10 \%$ for all samples that were distributed along the $20 \mathrm{~cm}$ long target. This agreement shows that calculation can well predict experimental results and that in this calibration experiment with $1 \mathrm{GeV}$ protons there are NO unresolved problems. The reaction is below the threshold [3] of $\mathrm{E}_{\mathrm{CM}} / \mathrm{u} \approx 150 \mathrm{MeV}$.

The results of the calibration experiment are shown together with two experiments with $44 \mathrm{GeV}^{12} \mathrm{C}$ onto the GAMMA-2 target [18] in Table 5. The average ratio of the experimental (exp) to the calculated neutron rate (cal) in the ${ }^{12} \mathrm{C}$ experiments is:

$$
\text { Neutron yield ratio in GAMMA }-2 \text { for } 44 \mathrm{GeV}^{12} \mathrm{C}:(\exp ) /(\mathrm{cal})=3.25 \pm 0.23
$$

which means that calculation can well reproduce the experiment at an energy below $\mathrm{E}_{\mathrm{CM}} / \mathrm{u} \approx 150 \mathrm{MeV}$ but it significantly underestimates neutron production above this threshold.

Another aspect of these GAMMA-2 target experiments was re-analyzed with an advanced theoretical model: These simulation calculations used the MCNPX2.7 Monte Carlo code implementing the INCL4 intra-nuclear cascade and the ABLA fission/evaporation model. The theoretical neutron yields were compared with the experimental yields of Ochs et al. [18]. The experiments involved the measurement of secondary neutrons via the radiochemical sensors ${ }^{140} \mathrm{La}$.

In the calculation of both ${ }^{2} \mathrm{H}$ and ${ }^{12} \mathrm{C}$ irradiations one finds the same increase in calculated neutron yields between 1.5 AGeV and $3.7 \mathrm{AGeV}$ of $(1.57 \pm 0.01)$, very similar to the yield ratios that have been obtained with the DCM/CEM [18] code.

In the experiment with ${ }^{2} \mathrm{H}$ projectiles a neutron yield increase by a factor of 5.59/4.60 = $1.22 \pm 0.12$ was

Table 5. Experimental (exp) and calculated (cal) neutron yields for $44 \mathrm{GeV}{ }^{12} \mathrm{C}$ and $1 \mathrm{GeV}{ }^{1} \mathrm{H}$ interactions in the $20 \mathrm{~cm}$ thick GAMMA-2 target.

\begin{tabular}{ccccc}
\hline & B $\left({ }^{140} \mathrm{La}\right)$ & Neutrons/ion & Neutrons/ion & Yield ratios \\
\hline Reaction & Experiment (exp) & Experiment (exp) & Calculation (cal) & (exp)/(cal) \\
\hline $1 \mathrm{GeV}^{1} \mathrm{H}+\mathrm{Pb}\left(^{*}\right)$ & $4.69 \pm 0.32[19]$ & 16 & $16\left(^{*}\right)$ & 1 \\
$44 \mathrm{GeV}^{12} \mathrm{C}+\mathrm{Cu}$ & $108 \pm 8[18]$ & $370 \pm 30$ & $115 \pm 10\left(^{* *}\right)$ & $3.2 \pm 0.4$ \\
$44 \mathrm{GeV}^{12} \mathrm{C}+\mathrm{Pb}$ & $266 \pm 19[18]$ & $900 \pm 70$ & $275 \pm 10\left(^{* *}\right)$ & $3.3 \pm 0.3$ \\
\hline
\end{tabular}

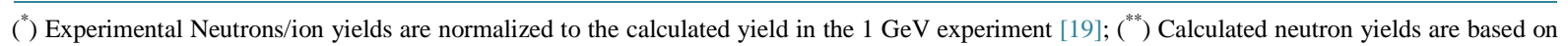
models MCNPX2a, LAHET and DCM/CEM, which yield very similar results [1] [18]. 
measured when the energy rose from $1.5 \mathrm{AGeV}$ to $3.7 \mathrm{AGeV}$, which is even smaller than calculated.

However, the experimental increase is significantly stronger for ${ }^{12} \mathrm{C}$ as projectile when going from $1.5 \mathrm{AGeV}$ to $3.7 \mathrm{AGeV}$ yielding a factor of $10.8 / 4.13=2.62 \pm 0.26$.

As the calculated increase of $\mathrm{B}$ for both ${ }^{2} \mathrm{H}$ and ${ }^{12} \mathrm{C}$ induced reactions is about the same factor of 1.57 whereas the experimental increase of $\mathrm{B}$ in the ${ }^{12} \mathrm{C}$ induced reaction is much larger it may well be assumed that in the ${ }^{12} \mathrm{C}$ reactions something happens which is not considered in the model calculation.

\subsubsection{Berkeley Experiment}

In the Berkeley experiment rather similar phenomena of exceedingly large neutron fluences were observed in the irradiation of a $20 \mathrm{~cm}$ thick Cu-target with $72 \mathrm{GeV}^{40} \mathrm{Ar}$ [1]. In contrast to the Dubna experiments, only one high-energy irradiation of a thick Cu-target was performed in Berkeley. No neutron measurements have been published but spallation product yields in $2 \mathrm{Cu}$-disks in contact (each disk $1.0 \mathrm{~cm}$ thick) have been extensively studied [20] in irradiations with $72 \mathrm{GeV}^{40} \mathrm{Ar}$ and $36 \mathrm{GeV}^{40} \mathrm{Ar}$. A large number of radioactive spallation product yields, $\left({ }^{\mathrm{A}} \mathrm{Z}\right)$, were measured and the analysis of the results revealed several unresolved problems, such as [3]:

- The yield-ratio $R_{0}{ }^{A} Z$ ) is defined as the activity of the nuclide $\left({ }^{A} Z\right)$ in the second (downstream) Cu-disk divided by the corresponding activity in the first (upstream) Cu-disk. These yield-ratios $\mathrm{R}_{0}{ }^{\mathrm{A}} \mathrm{Z}$ ) are expected to peak at a mass closely below the target mass, however, the maximum for these ratios $R_{0}\left({ }^{A} Z\right)$ is observed around mass $\mathrm{A} \approx 50$, i.e. far away from the target mass.

- The yield ratio $\left.R_{0}{ }^{A} \mathrm{Z}\right)$, for light spallation products, in particular for the isotope ${ }^{24} \mathrm{Na}$, is unexpectedly always $\mathrm{R}_{0}\left({ }^{24} \mathrm{Na}\right)>1.0$. This ratio is significantly larger than any calculation will predict [7].

Another detail observed for nuclides $\left({ }^{\mathrm{A}} \mathrm{Z}\right)$ which is important for discussions in the context of this paper is given in Figure 7. It shows the yield ratio $\mathrm{R}_{0}\left({ }^{\mathrm{A}} \mathrm{Z}\right)$ observed for irradiations with $72 \mathrm{GeV}^{40} \mathrm{Ar}$ on $\mathrm{Cu}$ divided by yield ratios $\mathrm{R}_{0}{ }^{\mathrm{A}} \mathrm{Z}$ ) observed for irradiations with $36 \mathrm{GeV}^{40} \mathrm{Ar}$ ions on $\mathrm{Cu}$ for all investigated radioactive spallation nuclides [20]:

$$
\mathrm{R}_{0}(72) / \mathrm{R}_{0}(36)=\left[\mathrm{R}_{0}\left({ }^{\mathrm{A}} \mathrm{Z}\right) \text { for } 72 \mathrm{GeV}^{40} \mathrm{Ar}\right] /\left[\mathrm{R}_{0}\left({ }^{\mathrm{A}} \mathrm{Z}\right) \text { for } 36 \mathrm{GeV}^{40} \mathrm{Ar}\right]
$$

For the higher Ar-projectile energy there is a significantly enhanced production of light spallation products $\left({ }^{\mathrm{A}} \mathrm{Z}\right)$ in the mass range $20<\mathrm{A}<30$ in the second Cu-disk. Any ratio exceeding unity is completely unexpected because one must assume that production of nuclides far away from the target or projectile mass requires plenty energy which is more abundant in the first disk than in the second one. It appears that reaction products (fragments) after the first interaction transfer energy much more effectively than the primary beam particle and this effect is even amplified with rising beam energy. No such enhanced energy transfer is experimentally seen below $\mathrm{E}_{\mathrm{CM}} / \mathrm{u} \approx 150 \mathrm{MeV}$.

It would be interesting to compare these radiochemical results with mass distributions from the investigation of $72 \mathrm{GeV}^{40} \mathrm{Ar}$ and $36 \mathrm{GeV}^{40} \mathrm{Ar}$ in nuclear emulsions. Unfortunately, relevant results from such a study are not

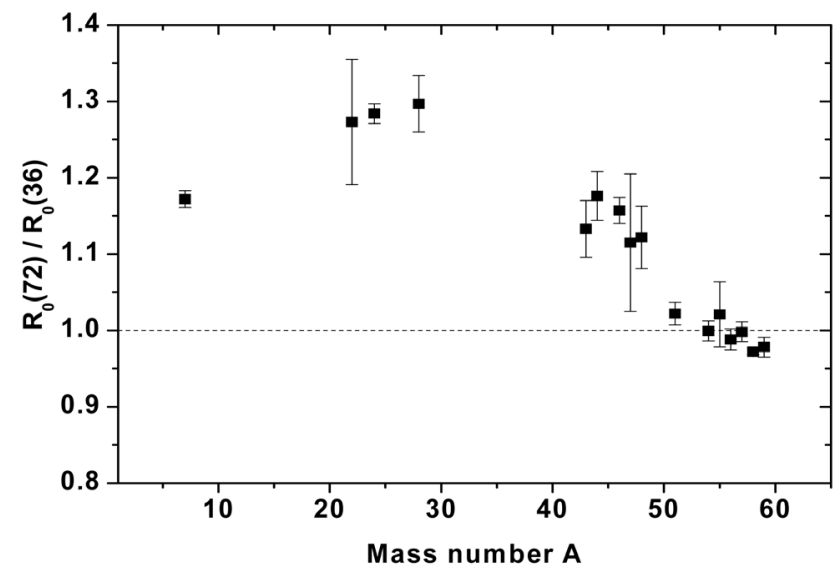

Figure 7. The yield ratio $\mathrm{R}_{0}\left({ }^{\mathrm{A}} \mathrm{Z}\right)$ observed in irradiations with $72 \mathrm{GeV}^{40} \mathrm{Ar}$ divided by the same yield ratios $R_{0}\left({ }^{A} Z\right)$ observed in irradiations with $36 \mathrm{GeV}^{40} \mathrm{Ar}$ ions as a function of product mass $<A>$. The data for the figure are taken from [20]. 
available to the authors. Therefore the second best choice was selected, i.e. the results of a study with $72 \mathrm{GeV}$

${ }^{22} \mathrm{Ne}$ presented earlier in this paper.

It was shown in Section 2.2 that the average mass loss through SPALLATION yields an average mass shift $\Delta \mathrm{A}=11.5 \mathrm{amu}$ (see Table 1). In BURST (bur) interactions, however, there is an increased charged-particle emission $\left(\left\langle\mathrm{N}_{\mathrm{s}}\right\rangle+\left\langle\mathrm{N}_{\mathrm{b}}\right\rangle\right)$ as compared to SPALLATION (spa) interactions (see Figure 4) as follows:

$$
\left(\left\langle\mathrm{N}_{\mathrm{s}}\right\rangle+\left\langle\mathrm{N}_{\mathrm{b}}\right\rangle\right)_{\text {bur/spa }}=(34.3 \pm 0.2) /(10.8 \pm 0.3)=(3.2 \pm 0.1)
$$

One may expect the same increase of the average mass shift for the residual nuclei in the mass-yield curve: The average mass for residual Cu-target nuclei in $72 \mathrm{GeV}{ }^{40} \mathrm{Ar}$ induced BURST interactions could then be expected around mass: $(63.3-3.2 \times 11.5) \mathrm{amu}=\mathbf{2 6 . 5} \mathbf{a m u}$. That mass is very close to ${ }^{24} \mathrm{Na}$ which is near the center of the peak in Figure 7. This may indicate that BURST interactions produce residual nuclei from the original target + projectile combination with a nuclear charge and mass considerably lower than SPALLATION interactions $d o$. The authors do not claim that this argument is convincing, but we think that an interesting correlation has been found. Further studies are certainly mandatory.

\section{Conclusions}

High-energy heavy ion interactions above a threshold of $\mathrm{E}_{\mathrm{CM}} / \mathrm{u} \approx 150 \mathrm{MeV}$ proceed in thick targets via two separate reaction channels:

- SPALLATION

- BURST

The first channel, SPALLATION, is well-understood and model calculations fit experimental data. The second channel, called BURST, releases 2 - 3 times more particles (protons, neutrons and pions) in the interaction. Its origin is unclear and there is no model known to the authors which calculates the observed phenomena. The rate of BURST reactions is enhanced when secondary reactions in thick targets are involved. The rate of BURST reactions increases significantly with increasing heavy ion energy and dominates by up to $80 \%$ in 72 $\mathrm{GeV}^{22} \mathrm{Ne}$ interactions in nuclear emulsions. This effect appears to be the reason for the observation of exceedingly large neutron fluences found in thick-target nuclear interactions.

- There are exceedingly large neutron fluences in interactions of $44 \mathrm{GeV}^{12} \mathrm{C}$ in $20 \mathrm{~cm}$ thick $\mathrm{Cu}$ - and Pb-targets and of $72 \mathrm{GeV}^{40} \mathrm{Ar}$ in $20 \mathrm{~cm}$ thick Cu-targets. The neutron fluence was measured in $44 \mathrm{GeV}^{12} \mathrm{C}$-induced reactions on $\mathrm{Cu}$ and $\mathrm{Pb}$ to be a factor of $(2-3)$ times larger than model-based MCNPX or DCM/CEM codes have calculated. These codes consider only conventional spallation interactions as known from thin-target experiments.

- Nuclear emulsions irradiated with $72 \mathrm{GeV}{ }^{22} \mathrm{Ne}$ ions allow a detailed study of both SPALLATION and BURST interactions. The fraction of BURSTS among all nuclear interactions [BUR/INT] is (26 \pm 4$) \%$ in the first interaction. This ratio (BUR/INT) increases up to about $80 \%$, when the 1st and 2nd interactions are considered together. Thus, because of their high abundance BURST-interactions must be considered simultaneously with SPALLATION-interactions in realistic descriptions of high-energy heavy ion interactions above the threshold of $\mathrm{E}_{\mathrm{CM}} / \mathrm{u} \approx 150 \mathrm{MeV}$. The number of charged-particles emitted per reaction (minimum ionizing particles plus black prongs) in BURST reactions is about a factor of (2 - 3) times larger than the corresponding number for SPALLATION reactions.

- A correlation between these two essential results depicting the finding [“a factor of (2 - 3) times larger”] obtained with completely different experimental techniques is considered: The enhanced number of chargedparticle emissions per interaction in BURSTS—as seen in nuclear emulsions-should be correlated with the observation of large neutron fluences measured with radiochemical methods in thick targets.

- Further studies are necessary, for conceptual as well as for practical reasons. There have been experiments with $200 \mathrm{GeV}^{238} \mathrm{U}$ in which the total breakup of the uranium ion into 92 singly charged ions was measured [9] [21]. This implies that 146 neutrons were produced as well. Reactions of this type require careful radiation safety measures in new heavy-ion accelerators which provide multi-GeV per nucleon ions up to $400 \mathrm{GeV}^{238} \mathrm{U}$ or above.

\section{References}

[1] Ganssauge, E., Westmeier, W. and Brandt, R. (2013) Potential Correlations between Unexplained Experimental Ob- 
servables and Hot Projectile-Like Fragments in Primary Interactions above $\mathrm{E}_{\mathrm{CM}} / \mathrm{u} \approx 150 \mathrm{MeV}$. World Journal of Nuclear Science and Technology, 3, 155-161.

[2] Hashemi-Nezhad, S.R., Zamani-Valasiadou, M., Krivopustov, M.I., Brandt, R., Ensinger, W., Odoj, R. and Westmeier, W. (2011) Neutron Production in Thick Targets Irradiated With High Energy Ions. Physics Research International, 2011, Article ID: 128429.

[3] Westmeier, W., Brandt, R., Hashemi-Nezhad, S.R., Odoj, R., Sosnin, A.N., Ensinger, W. and Zamani-Valasiadou, M. (2012) Correlations in Nuclear Interactions between $\mathrm{E}_{\mathrm{CM}} / \mathrm{u}$ and Unexplained Experimental Observables. World Journal of Nuclear Science and Technology, 2, 125-132. http://dx.doi.org/10.4236/wjnst.2012.24019

[4] (1996) Private Letter of the Late Professor E. Schopper (Frankfurt) to R.B. dated December 12, 1996.

[5] Tolstov, K.D. (1991) Some Peculiarities of Relativistic Nucleus Collisions. International Journal of Radiation Applications and Instrumentation Part D: Nuclear Tracks and Radiation Measurements, 19, 657-664.

[6] Cumming, J.B., Haustein, R.E., Ruth, T.J. and Virtes, G.J. (1978) Spallation of Copper by $80 \mathrm{GeV}^{40} \mathrm{Ar}$ Ions. Physical Review C, 17, 1632-1641.

[7] Brandt R., Ditlov V.A., Dwivedi K.K., Ensinger W., Ganssauge E., Guo, S.-L., Haiduc, M., Hashemi-Nezhad, S.R., Khan, H.A., Krivopustov, M.I., Odoj, R., Pozharova, E.A., Smirnitzki, V.A., Sosnin, A.N., Westmeier, W. and Zamani-Valasiadou, M. (2008) Interactions of Relativistic Heavy Ions in Thick Heavy Element Targets and Some Unresolved Problems. Physics of Elementary Particles and Nuclei, 39, 507-526 (Original). (Reprinted: Physics of Particles and Nuclei, 39, 259-285.)

[8] Friedlander, E.M., Gimpel, R.W., Heckman, H.H., Karant, Y.J., Judek, B. and Ganssauge, E. (1983) Anomalous Reaction Mean Free Path of Nuclear Projectile Fragments from Heavy Ion Collisions at 2 AGeV. Physical Review C, 27, 1489-1519.

[9] Ganssauge, E. (1987) Der Experimentelle Stand der Anomalonen-Forschung Annalen der Physik, 7. Folge, 11, 202-246.

[10] Szilard, L. (1929) Über die Entropieverminderung in Einem Thermodynamischen System bei Eingriffen Intelligenter Wesen. Zeitschrift für Physik, 53, 840-856.

[11] Ochs, M. (1997) Fachbereich Physikalische Chemie. Dissertation, Philipps-Universität, Marburg.

[12] Haase, G. (1990) Fachbereich Physikalische Chemie. Dissertation, Philipps-Universität, Marburg.

[13] Brandt, R. (1999) Measurements of Neutron Yields and Radioactive Isotope Transmutation in Collisions of Relativistic Ions with Heavy Target Nuclei. Report for the 85th Session of the JINR Scientific Council, Joint Institute for Nuclear Research, Dubna.

[14] Ditlov, V.A., Dubinina, V.V., Krotkova, V.I., Pozharova, E.A., Smirnitzky, V.A., Brandt, R. and Ensinger, W. (2005) Study of the Number of Black Prongs in Two Generations of Nuclear Interactions in Photoemulsions Irradiated by 72 $\mathrm{GeV}^{22} \mathrm{Ne}$. Radiation Measurements, 40, 448-459.

[15] Ditlov, V.A., Dubinina, V.V., Krotkova, V.I., Pozharova, E.A., Smirnitzky, V.A., Brandt, R., Westmeier, W. and Ensinger, W. (2006) Distribution of Black Prong Numbers of Fragments Measured in Two Generations of Nuclear Interactions in Photoemulsion Irradiated with $72 \mathrm{GeV}{ }^{22} \mathrm{Ne}$. Poster Presented at the XX International Conference on SSNTD, Beijing (Unpublished).

[16] Haiduc, M., Firu, E. and Neagu, A.T. (2012) Internal Report from “Bucharest Institute of Space Sciences”. Bucharest, (Unpublished).

[17] Pille, F. (1989) Technische Hochschule Leipzig. Dissertation (A) (Unpublished).

[18] Ochs, M., Abdullaev, I.G., Adam, J., Adloff, J.C., Bersina, I.G., Bradnova, V., Brandt, R., Bognitzki, M., Butsev, V.S., Debeauvais, M., Dwivedi, K.K., Fernandez, F., Guo, S.-L., Krivopustov, M.I., Kulakov, B.A., Langrock, E.-J., Modolo, G., Odoj, R., Perelygin, V. P., Premyshev, A.N., Pronskich, V.S., Schmidt, Th., Sosnin, A.N., Stegailov, V.I., Sudowe, R., Vater, P., Wan, J.-S., Zamani, M. and Zupko-Sitnikov, V.M. (1997) SSNTD and Radiochemical Studies on the Transmutation of Nuclei UsingRelativistic Ions. Radiation Measurements, 28, 255-268. http://dx.doi.org/10.1016/S1350-4487(97)00078-4

[19] Westmeier, W., Odoj, R., Tyutyunnikov, S.I., Hashemi-Nezhad, S.R., Ensinger, W., Zamani-Valasiadou, M., Brandt, R. and Thomauske, B. (2011) Experimente zur Transmutation Langlebiger Radioaktiver Abfälle. atw International Journal for Nuclear Energy, 56, 620-628.

[20] Aleklett, K., Brandt, R., Dersch, G., Feige, G., Friedlander, E.M., Ganssauge, E., Haase, G., Herrmann, J., Judek, B., McGaughey, P.L., Loveland, W., Porile, N.T., Schulz, W. and Seaborg, G.T. (1991) Erratum: Unusual Interaction of Projectile Fragments Produced by Relativistic Ar in Copper. Physical Review C, 44, 566.

http://dx.doi.org/10.1103/PhysRevC.44.566 
[21] Khan, H.A., Brandt, R., Kraft, G., Kraft-Weyrather, W. and Khan, N.A. (1991) Exceptionally High Multiplicity Events Observed in the Interaction of Relativistic Uranium Ions with Light Target Atoms. Nuclear Instruments and Methods in Physical Research B, 61, 497-501. http://dx.doi.org/10.1016/0168-583X(91)95328-B 